Gut, 1989, 30, 1396-1400

\title{
Effects of non-shunting operation on azygos venous blood flow in cirrhotic patients
}

\author{
N KOKUDO, S KAWASAKI, K OHASHI, H SAKAMOTO, H KOYAMA, \\ K SANJO, AND Y IDEZUKI \\ From the Second Department of Surgery, Faculty of Medicine, University of Tokyo, Tokyo, Japan
}

\begin{abstract}
SUMmary Azygos venous blood flow and other haemodynamic parameters were measured in 14 cirrhotic patients to investigate the effects of a non-shunting operation, oesophageal transection with paraoesophagogastric devascularisation. Azygos venous blood flow measured by the local continuous thermal dilution method was significantly reduced by $13.8 \%$ after the operation $(428(41) v$ 369 (33) $\mathrm{ml} / \mathrm{min}$ ). Hepatic venous pressure gradient (HVPG) was also significantly decreased from $14.5(0.8)$ to $12 \cdot 8(0 \cdot 7) \mathrm{mmHg}(-11 \cdot 8 \%)$. Cardiac output and routine liver tests did not change remarkably postoperatively. In this haemodynamic study before and after non-shunting operation, moderate but significant decreases were seen in azygos venous blood flow and portal pressure (HVPG), without substantial changes in systemic circulation. This suggests that blood flow through the portosystemic collaterals other than oesophageal varices may be decreased but still adequate after the operation. Well preserved portosystemic collaterals without oesophageal varices are thus considered an optimally balanced state after non-shunting operation.
\end{abstract}

In patients with portal hypertension, measurement of the azygos venous blood flow has recently been shown to provide a quantitative estimation of blood flow through superior portosystemic collaterals draining into the azygos venous system.' Although azygos venous blood flow change caused by some pharmacological agents, such as propranolol, ,? vasopressin, ${ }^{4}$ metoclopamide and domperidone, ${ }^{5}$ has been investigated, there have been few reports on the effects of surgical procedures for portal hypertension.'

In this study, we examine the effects of oesophageal transection with paraoesophagogastric devascularisation ${ }^{6}$ on azygos venous blood flow in patients with liver cirrhosis.

\section{Methods}

PATIENTS

Fourteen patients (10 men, aged 32-70 years $(54 \cdot 2)$ ) suffering from cirrhosis of the liver were included in

Address for correspondence: Dr Norihiro Kokudo, Second Department of Surgery. Faculty of Medicine. University of Tokyo, Bunkyo-ku, Tokyo 113. Japan.

Accepted for publication 14 February 1989 this study (Table 1). All showed severe portal hypertension with large oesophageal varices. The diagnosis was confirmed by intraoperative liver biopsy. The aetiology of the disease was alcoholic in three patients and non-alcoholic in 11. HBs antigen was positive in three of the 11 non-alcoholic patients. The size of the oesophageal varices was examined endoscopically, and the form of the varices $(F)$ was classified according the general rules for recording endoscopic findings on oesophageal varices of the Japanese Research Society for Portal Hypertension." Specifically, F1: straight shaped varices; F2: slightly enlarged tortuous varices occupying less than onethird of the oesophageal lumen; F3: the largest size varices which are coil shaped and occupy more than one-third of the oesophageal lumen.

In all patients except one (case 7), direct operation involving splenectomy with oesophagogastric devascularisation and oesophageal transection was performed without any resulting complications. Hassab's procedure - that is, splenectomy with oesophagogastric devascularisation ${ }^{4}$ was undertaken in case 7. In case 4 , partial liver resection was also performed for an accompanying small hepatocellular carcinoma.

A control group for comparative analysis was 
Table 1 Clinical and biochemical data of 14 patients with liver cirrhosis

\begin{tabular}{|c|c|c|c|c|c|c|c|c|c|c|}
\hline Patie'nt & $\begin{array}{l}\text { Age } \\
y r 1\end{array}$ & $\operatorname{sex}$ & $\begin{array}{l}\text { Childs } \\
\text { Class }\end{array}$ & Varices & $\begin{array}{l}\text { Serum } \\
\text { alhumin } \\
(\mathrm{g} / \mathrm{l})\end{array}$ & $\begin{array}{l}\text { Serum } \\
\text { bilirubin } \\
\text { (umollll) }\end{array}$ & $\begin{array}{l}I C G \\
R I 5^{*} \\
(\%)\end{array}$ & $\begin{array}{l}I C G \\
-k^{\dagger} \\
(\min )\end{array}$ & $\begin{array}{l}\text { Prothrombin } \\
\text { time } \\
(\%)\end{array}$ & $\begin{array}{l}\text { Splenic } \\
\text { weight } \\
\text { (g) }\end{array}$ \\
\hline $1 \mathrm{KK}$ & $5 x$ & .11 & $A$ & $\mathrm{~F} 3$ & 37 & $10 \cdot 2$ & $21 \cdot 7$ & 0.129 & 66 & 370 \\
\hline $2 M Y$ & 70 & $\mathrm{~F}$ & $A$ & $\mathrm{~F}$ ? & 38 & $8 \cdot 5$ & $11 \cdot 3$ & $0 \cdot 139$ & 82 & 190 \\
\hline 3 MS & 32 & $\mathrm{~F}$ & $A$ & $\mathrm{~F} 3$ & 39 & $8 \cdot 5$ & $6 \cdot 8$ & 0.139 & 103 & 35() \\
\hline+ SS & $\therefore$ & .11 & $A$ & F3 & 38 & $23 \cdot 8$ & 21.9 & $0 .(179$ & 66 & 252 \\
\hline $5 \mathrm{KO}$ & 51 & 11 & $A$ & F3 & 36 & $15 \cdot 3$ & $3(1) \cdot 5$ & $0 .(074$ & 55 & 380 \\
\hline h $\quad$ NS & in & 11 & $\mathrm{C}$ & F2 & 26 & $3(0) \cdot 6$ & $46 \cdot 1$ & 0.069 & 56 & 230 \\
\hline $7 \mathrm{FM}$ & 54 & $\mathrm{~F}$ & B & $\mathrm{F} 3$ & 32 & 201.4 & $26 \cdot 0$ & $0 .(184$ & 54 & 145 \\
\hline$\times \quad T K$ & 56 & in & B & F3 & 33 & $23 \cdot 8$ & $67 \cdot 1$ & 0.016 & 59 & 290 \\
\hline $9 \mathrm{TI}$ & +1 & .11 & $A$ & $F^{2}$ & 4.3 & 201.4 & $2(1) \cdot 1$ & 0.112 & 55 & 410 \\
\hline $10 \mathrm{HK}$ & 5) & .11 & B & $F_{2} 2$ & 34 & $10) \cdot 2$ & 21.5 & 0.086 & 67 & 510 \\
\hline $11 \mathrm{YY}$ & 6? & $\mathrm{F}$ & C & $\mathrm{F} 3$ & 28 & $10 \cdot 2$ & 31.5 & 0.082 & 64 & 320 \\
\hline 12 TK & 5y & 11 & $A$ & $\mathrm{~F} 2$ & 37 & 11.9 & $11 \cdot 4$ & 0.151 & 64 & 295 \\
\hline 13 TK & $\therefore$ & 11 & $A$ & $\mathrm{~F} 3$ & 36 & $18 \cdot 7$ & 48.4 & $0 .(017$ & 64 & 36() \\
\hline 14 EK & is & 11 & $A$ & $\mathrm{~F}^{2}$ & 38 & $22 \cdot 1$ & $30 \cdot 8$ & $0 .(175$ & 55 & 300 \\
\hline $\begin{array}{l}\text { Mean } \\
\text { (SE) }\end{array}$ & $\begin{array}{l}54 \cdot 2 \\
(2.51\end{array}$ & & & & $\begin{array}{l}35.4 \\
(1.2)\end{array}$ & $\begin{array}{l}16 \cdot 8 \\
(1.9)\end{array}$ & $\begin{array}{l}28 \cdot 2 \\
(4 \cdot 4)\end{array}$ & $\begin{array}{c}0 \cdot(089 \\
(0 \cdot() 11)\end{array}$ & $\begin{array}{l}6.5 \cdot() \\
(3.5)\end{array}$ & $\begin{array}{l}314 \\
(25)\end{array}$ \\
\hline
\end{tabular}

$\$ 15$ minutes retention rate of Indocyanine green (ICG) after intravenous administration $(0.5 \mathrm{mg} / \mathrm{kg})$ : †plasma disappearance rate of ICG after intravenous administration $(0.5 \mathrm{mg} / \mathrm{kg})$.

provided by measuring azygos venous blood flow in four non-cirrhotic patients, three with small colorectal hepatic metastasis and one with oesophageal cancer. Haemodinamic data in these control patients are given in Table 2. All patients gave their informed consent to take part in this study.

After overnight fasting, haemodynamic studies, including azigos venous blood flow, cardiac output and hepatic venous pressure, were performed with the patients supine. These measurements were made before and approximately one month after oesophageal transection. splenectomy, and oesophagogastric devascularisation. All measurements were completed within one hour, during which each patient's condition was stable. With the patients under local anaesthesia. an $8 \mathrm{~F}$ venous catheter introducer (Cordis Corporation, Miami, Fl, USA) was placed in the femoral vein in order to introduce different catheters.

Azygos venous blood flow was measured with the local continuous thermal dilution method using the previously described technique. " "'Briefly, the azygos vein was catheterised with a continuous thermodilution catheter (Webster Laboratories Inc, Altadena, Cal, USA). The catheter was advanced into the azygos vein under fluoroscopic control up to $5 \mathrm{~cm}$ from its junction with the superior vena cava. The position of the catheter was checked by $x$-ray examination so that the postoperative study in each patient could be made under a similar condition. The constant rate of infusion of the indicator $(5 \%$ dextrose) ranged from 30 to $40 \mathrm{ml} / \mathrm{min}$.

Azygos venous blood flow was calculated using the continuous thermal dilution equation,

$$
\begin{gathered}
\text { Blood flow }(\mathrm{ml} / \mathrm{min})= \\
\mathrm{F}(\mathrm{I}) * 1 \cdot 08 *\left(\frac{\mathrm{T}(\mathrm{B})-\mathrm{T}(\mathrm{I})}{\mathrm{T}(\mathrm{B})-\mathrm{T}(\mathrm{M})}-1\right)
\end{gathered}
$$

Here, $F(I)$ is the rate of indicator infusion, 1.08 is a constant representing the ratio between the density and specific heat of 5\% dextrose and blood, T(B) is the baseline azygos blood temperature $(\mathrm{C}), \mathrm{T}(\mathrm{I})$ is

\begin{tabular}{|c|c|c|c|c|c|c|}
\hline Patie'nt & Age (ly & $\operatorname{sex}$ & $A=B F(\mathrm{ml} / \mathrm{min})$ & $H V P(g(m m H g)$ & $\mathrm{CO}(1 / \mathrm{min})$ & $A=B F / C O(\%)$ \\
\hline $\mathrm{SH}$ & $\therefore 3$ & $\mathrm{M}$ & 74 & 3 & - & - \\
\hline $\mathrm{KM}$ & it & $\mathrm{M}$ & 2017 & 3 & 6.98 & $3.1)$ \\
\hline MT & his & $\mathrm{M}$ & $2(k)$ & 4 & $6 \cdot 10$ & $3 \cdot 3$ \\
\hline YF & 511 & $\mathrm{~F}$ & 170 & 2 & 5.30 & $3 \cdot 2$ \\
\hline $\begin{array}{l}\text { Mean } \\
\text { (SE) }\end{array}$ & $\begin{array}{l}5.4 \\
(5.1)\end{array}$ & & $\begin{array}{l}163 \\
(31)\end{array}$ & $\begin{array}{c}3 \cdot() \\
(1) \cdot 4)\end{array}$ & $\begin{array}{c}6 \cdot 13 \\
(0.48)\end{array}$ & $\begin{array}{c}3 \cdot 2 \\
(0 \cdot 1)\end{array}$ \\
\hline
\end{tabular}

Table 2 Haemodynamic duta in non-cirrhotic patients

AzBF: Azygos renour hlood flow: HVPG: Hepatic venous pressure gradient: CO: Cardiac output. 
the temperature of the blood indicator mixture during indicator infusion $(C)$. The mean values during several breathing cycles were calculated with a microcomputer (AMCO Company, Tokyo, Japan).

Cardiac output was measured using the thermodilution method with a Swan-Ganz catheter (Edwards Laboratories, Santa Ana, Cal, USA) introduced into a pulmonary artery. "The fractional distribution of cardiac output to azygos venous bed (azygos venous blood flow/cardiac output $(\%): \mathrm{AzBF} / \mathrm{CO}(\%))$ was calculated in order to cancel the effect of systemic circulation fluctuation represented by cardiac output.

Hepatic venous pressure was measured with an $8 \mathrm{~F}$ balloon tipped catheter (Johnson-Johnson Company, Tampa, Fl, USA) placed in the main right hepatic vein. Wedged (occluded) and free hepatic venous pressures were obtained by inflating and releasing the balloon. The gradient between the wedged and free hepatic venous pressures (hepatic venous pressure gradient:HVPG) was calculated as an indicator of portal pressure. ${ }^{\prime 2}$

Routine liver tests including S-bilirubin, S-aspartate transaminase (S-AST), S-alanine transaminase (S-ALT), S-cholinesterase, and prothrombin time were checked before and about one month after the operation.

STATISTICAL ANALYSIS

The data presented in the text and in the Tables are expressed as mean (SE). Student's $t$ test was used in the statistical analysis of the results. A p value of less than or equal to 0.05 was considered statistically significant.

\section{Results}

AZYGOS VENOUS BLOOD FLOW BEFORE AND

AFTER OPERATION (Table 3)

Preoperative azygos venous blood flow ranged from 136 to $785 \mathrm{ml} / \mathrm{min}$ with an average of $428(41)$, being raised to approximately three times the amount of the non-cirrhotic controls (163 (31) $\mathrm{ml} / \mathrm{min}, \mathrm{n}=4$, $p<0 \cdot 02$, Table 2). Azygos venous blood flow was significantly reduced by $13 \cdot 8 \%$ after the operation $(\mathrm{p}<0.02)$. The postoperative value $(369(33) \mathrm{ml} / \mathrm{min})$ was still significantly higher than the non-cirrhotic controls $(p<0 \cdot 02)$. No correlation was apparent between the azygos venous blood flow change and splenic weight.

\section{OTHER HAEMODYNAMIC PARAMETERS BEFORE}

\section{AND AFTER OPERATION}

A moderately significant decrease in HVPG from $14.5(0.8)$ to $12.8(0.7) \mathrm{mmHg}$ (a change of $11.8 \%$, $\mathrm{p}<0.02)$ was seen after the operation. Both values were significantly higher than those of the control group $(\mathrm{p}<0.01)$. On the other hand, cardiac output did not significantly change postoperatively (from $6 \cdot 11(0.50)$ to $6 \cdot 74(0.65) \mathrm{l} / \mathrm{min})$. AzBF/CO $(\%)$ was significantly reduced by $19.7 \%$ (from $7.63(1.06)$ to $6 \cdot 13(0 \cdot 85) \%, p<0 \cdot 05)$ after the operation.

SIZE OF VARICES AND ROUTINE LIVER TESTS

BEFORE AND AFTER OPERATION

The preoperative size of oesophageal varices is given in Table 1. They disappeared completely in 12 patients. Small - that is, F1 varices still existed in case 4 (with hepatocellular carcinoma) and in case 7 (after

Table 3 Azygos venous blood flow and other haemodynamic parameters before and after non-shunting operation

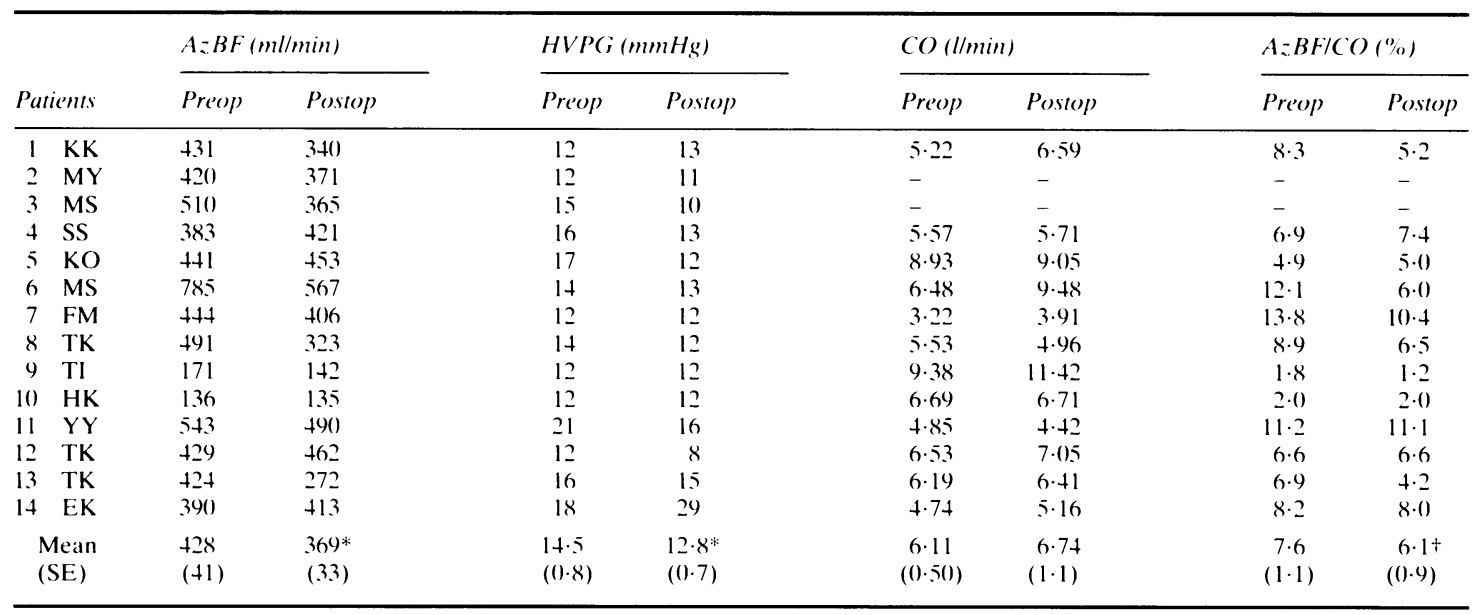

AzBF: Azygos venous blood flow: HVPG: Hepatic venous pressure gradient: CO: Cardiac output: *Significantly different from the preoperative values $(p<0 \cdot(2)): \div$ Significantly different from the preoperative values $(p<0 \cdot(15)$. 
Table 4 Laboratory data before and after non-shunting operation

\begin{tabular}{lcc}
\hline & Before & After \\
\hline S-Bilirubin $(\mu \mathrm{mol} / 1)^{*}$ & $16 \cdot 8(1 \cdot 9) \div$ & $16 \cdot 8(2 \cdot 7)$ \\
S-AST $(\mathrm{U} / \mathrm{l})$ & $54 \cdot 4(9 \cdot(0)$ & $63 \cdot 1(9 \cdot 8)$ \\
S-ALT $(\mathrm{U} / \mathrm{l})$ & $53 \cdot 1(9 \cdot 1)$ & $48 \cdot 6(6 \cdot 6)$ \\
S-Cholinesterase $(\mathrm{U} / \mathrm{l}) \div$ & $239(23)$ & $21.5(26)$ \\
Prothrombin time $(\%)$ & $6.0(3)$ & $65 \cdot 8(4 \cdot 4)$ \\
\hline
\end{tabular}

S-AST: Serum aspartate transaminase $(8 \sim 3.3 \mathrm{U} / \mathrm{l})$ : S-ALT: Serum alanine transaminase (4 3.3 U/l): *3.4 22.1 $\mu \mathrm{mol} / \mathrm{l}:$ t mean (SE): $\$ 36() \sim 7(1) 5 \mathrm{U} / \mathrm{l}$ (male). 320 $66.5 \mathrm{U} / \mathrm{l}$ (female).

Hassab's operaton). Routine liver tests including S-bilirubin, S-AST, S-ALT, S-cholinesterase and prothrombin time did not significantly change after the non-shunting operation.

\section{Discussion}

Satisfactory results of the operation consisting of oesophageal transection, splenectomy and oesophagogastric devascularisation have been well documented, ${ }^{13}$ and some reports have appeared concerning portographic changes after the surgical procedure." To clarify the portosystemic collateral changes that take place after the operation, azygos venous blood flow and other haemodynamic parameters were measured before and after the operation.

Although the significant reduction in azygos venous blood flow after surgery might be considered quite convincing, the postoperative values were still unexpectedly high compared with those of the noncirrhotic controls. The most likely explanation for these results is as follows: the azygos system drains not only the blood which lies in the oesophageal varices but also the paraoesophageal and mediastinal channels. ${ }^{1+}$ After the surgical procedure, blood flow through the oesophageal varices and some parts of the paraoesophageal collaterals is extirpated. Variceal blood flow has recently been reported as possibly being low in some patients with cirrhosis because Doppler ultrasound probes have shown that variceal blood velocity varied in both directions according to respiration. ${ }^{15}$ If variceal blood flow is low in spite of the apparent size of the varices, ocsophageal transection will contribute only slightly to reducing azygos venous blood flow.

Some parts of the paraoesophageal collaterals are also interrupted after oesophagogastric devascularisation. Preserved - that is, not devascularised - parts of paraoesophageal collaterals and mediastinal channels are considered to be the major collaterals draining into the azygos system one month after the operation. As portal pressure (HVPG) was still high

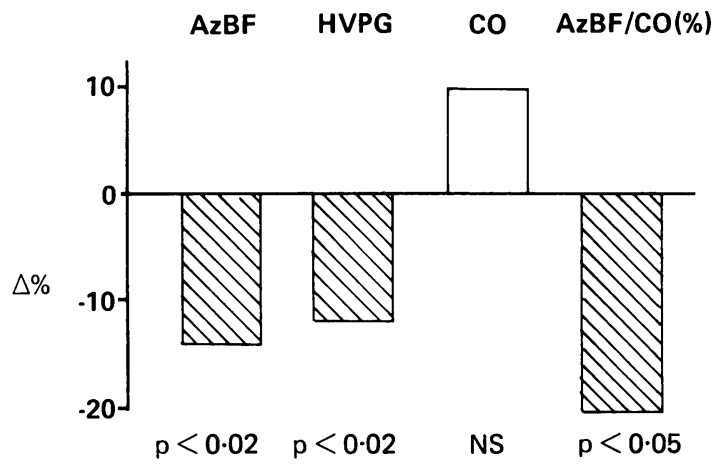

Figure Effects of non-shunting operation on azygos venous blood flow $(A=B F)$, hepatic venous pressure gradient (HVPG), cardiac output $(C O)$ and $A=B F / C O(\%) . N S=n o t$ significant.

postoperatively, blood flow through the preserved collaterals draining into the azygos venous system was expected to be maintained to a considerable extent.

It is not certain how the reduction in inflow into the portal system after splenectomy affects the collateral circulation represented by azygos venous blood flow. No correlation was noted between the azygos venous blood flow change and splenic weight. Splenic blood flow measured using inert radioactive xenon technique has been reported as being from 45 to 70 $\mathrm{ml} / \mathrm{min}$ per $100 \mathrm{~g}$ of spleen in cirrhotic patients. ${ }^{1617} \mathrm{In}$ this study, splenic weight ranged 145 to $510 \mathrm{~g}$, with an average of $314 \mathrm{~g}$, which is relatively small. The mean splenic blood flow, which is considered to be equal to the inflow reduction just after splenectomy, is thus calculated to be from 140 to $220 \mathrm{ml} / \mathrm{min}$. It must also be kept in mind that alterations in superior mesenteric arterial flow in response to inflow reduction after splenectomy affect the portal circulation. ${ }^{1 \mathrm{~W}} \mathrm{We}$ suggest that after the operation superior mesenteric and hepatic arterial blood flows be increased to maintain sufficient perfusion for the cirrhotic liver.

The hacmodynamic effects of the non-shunting operation are summarised in the Figure. In this haemodynamic study before and after the operation, moderate but significant decreases were seen in azygos venous blood flow and portal pressure (HVPG), with no substantial changes noted in systemic circulation. Well preserved hepatic blood flow $^{14}$ and portosystemic collaterals without oesophageal varices are thus considered an optimally balanced state after the operation.

\section{References}

I Bosch J. Groszmann RJ. Measurement of azygos venous flow by a continuous thermal dilution technique: 
an index of blood flow through gastroesophageal collaterals in cirrhosis. Hepatology 1984; 4: 424-9.

2 Bosch J, Mastai R, Kravetz D, Bruix J, Gaya J, Rigau J, Rodes J. Effects of propranolol on azygos venous blood flow and hepatic and systemic hemodynamics in cirrhosis. Hepatology 1984; 4: 1200-5.

3 Cales P, Braillon A, Jiron 1, Lebrec D. Superior portosystemic collateral circulation estimated by azygos blood flow in patients with cirrhosis. $J$ Heptaol 1984; 1: 37-46.

4 Bosch J, Kravetz D, Mastai R, Bruix J, Rigau J. Rodes J. Azygos venous blood flow in cirrhosis: effects of balloon tamponade, vasopressin, somatostatin and propranolol [Abstract]. Hepatology 1983; 3: 855.

5 Mastai R, Grande L, Bosch J, et al. Effects of metoclopamide and domperidone on azygos venous blood flow in patients with cirrhosis and portal hypertension. Hepatology 1986; 6: 1244-7.

6 Idezuki Y, Sugiura M, Sakamoto K. Abe H, Miura T. Hatano S, Kimoto S: Rationale for transthoracic esophageal transection for blecding varices. Dis Chest 1967; 52: $621-31$.

7 Sugiura M, Futagawa S. A new technique for treating esophageal varices. J Thorac Cardiovasc Surg 1973; 66: 677-85.

8 Japanese Rescarch Socicty for Portal Hypertension. The general rules for recording esophageal varices. $J p n$ J Surg 1980; 10: 84-7.

9 Hassab MA. Gastroesophageal decongestion and splenectomy in the treatment of esophageal varices in Bilharzial cirrhosis: further studies with a report on 355 operations. Surgery 1967; 61: 169-76.

10 Ganz W. Tamura K. Marcus H, Donoso R, Yoshida S.
Swan H. Measurement of coronary sinus blood flow by continuous thermodilution in man. Circulation 1971: 44: $181-95$.

11 Ganz W. Denoso R. Marcus H. Forrester J. Swan H. A new technique for measurement of cardiac output by thermodilution in man. Am J Cardiology 1971; 27: 3926.

12 Groszmann RJ, Glickman M. Blei AT. Storer E. Conn $\mathrm{H}$. Wedged and free hepatic venous pressure measured with a balloon catheter. Gastroenterology 1979: 76: $253-8$.

13 Sugiura M. Futagawa S. Further evaluation of the Sugiura procedure in the treatment of esophageal varices. Arch Surg 1977: 112: 1317-21.

14 Murray J: Role of the azygos venous system in the investigation of portal hypertension. Gut 1966; 7: 94-8.

15 McCormack TT. Rose JD. Smith PM. Johnson AG: Perforating veins and blood flow in oesophageal varices. Lancet 1983; ii: 1442-4.

16 Williams R. Condon RE. Williams HS, Blendis LM, Kreel L. Splenic blood flow in cirrhosis and portal hypertension. Clin Sci 1968; 34: 441-52.

17 Gitlin N. Grahame GR, Krecl L. Williams HS, Sherlock S. Splenic blood flow and resistance in patients with cirrhosis before and after portacaval anastomosis. Gastroenterology 1970; 59: 208-13.

18 Dumont AE, Berman IR, Stahl WM, Ring SM: Significance of an enlarged splenic artery in patients with blecding varices. Ann Surg 1972; 175: 466-71.

19 Kawasaki S, Kidokoro A. Sugiura M, Sanjo K. Idezuki $Y$ : Effects of nonshunting operations on portal venous pressure and hepatic blood flow. Am J Surg 1987; 153: $29.5-8$. 